\title{
Building E-Learning Content Repositories to Support Content Reusability
}

\author{
http://dx.doi.org/10.3991/ijet.v9i3.3456 \\ J. Marciniak \\ Adam Mickiewicz University, Poznań, Poland
}

\begin{abstract}
The paper presents the method and tools to build repositories of digitalized didactic materials to support their reusability. The method consists of a set of recommendations for the structuring of didactic materials and of a way to assign unambiguous didactic interpretation to sections of materials by means of UCTS. UCTS (i.e. Universal Curricular Taxonomy System) is a taxonomic system designed to situate learning content in the didactic process. Using this system to mark parts of materials ensures that users will access materials that are cohesive and relevant without the risk of downloading from the repository incomplete chunks of content. Such guarantee is indispensable in massive repositories, which are created and used by numerous users, and which contain non-uniform content. An important component of the presented method is dedicated software Content Repository Tool, which was designed to store and process didactic content with the ability to reuse it in different educational contexts. This software enables creation of single- or multi-topic repositories with the possibility to create distributed repositories.
\end{abstract}

Index Terms-e-learning digital libraries, content reusability, UCTS, tools for e-learning

\section{INTRODUCTION}

A repository of didactic materials is an IT solution used to digitally store, process and retrieve didactic content. Repositories can be made in different ways, subject to form of materials, availability of technical infrastructure, or user habits and IT skills. A simple solution enabling digital storage of files can be considered a repository of didactic materials. Also, a dedicated IT system which requires materials structured according to a imposed specification and recorded in a selected technical standard can be considered a repository. The type of technical solution used to create a repository is correlated to technical standard in which didactic materials are recorded, and to their role in the process of distance learning.

Technical standard of digitalized materials may be diverse and may be analyzed on many levels. The basic level is the type of technical format the components are recorded in, i.e. whether they are HTML files, pdf documents or pg images, etc. Moreover, files may be unconnected or grouped. In the latter case, a variety of technical solutions may be used to group contents: files may be simply archived (e.g. as zip files) or they may be aggregated by means of a dedicated specification that guarantees portability (e.g. SCORM, AICC, Tin Can). The choice of standard is correlated to the type of authoring tool that the author had at his/her disposal. It is essential that prior to creating a repository, a technical structure must be selected that will support reusability of the content and its components.
In order to construct flexible content repositories supporting reusability it is essential for teaching materials to be constructed in such a way that they can be easily modified and repeatedly used. First of all they should have a form allowing for construction of larger structures with smaller units; also they should be registered in such a technical specification which will enable flexible processing. And specifications such as SCORM as well as division into Learning Objects meet this requirement. Another element which is necessary is the mechanism of granting didactic interpretation to those sections of materials which are cohesive and useful didactically. Such sections are designed to be used in many various educational contexts, different from that in which they were initially placed. In the method presented here didactic interpretation is given by means of UCTS nomenclature (Universal Curricular Taxonomy System). This method enables a uniform description of the content regardless of their character or educational context in which they are to be used.

Repositories of didactic content supporting reusability are created so that materials developed by one author can be used by other didacticians either in their entirety (as a complete training program) or in part. Digitalized didactic content can be incorporated in the distance teaching process in various ways depending on the methodology used. It can be used as support and supplement to the didactic process conducted in a traditional setting (i.e. in the classroom), or it can serve as core source of knowledge which replaces the teacher in the process of asynchronous distance learning. Notwithstanding its role it is essential, however, that didactic content is suited to the specificity and needs of target groups. Therefore, it is vital that in the process of working with the repository the teacher should be able to adapt materials to such needs. This comes down to constructing new materials from the existing components. Those new materials can differ to a lesser or higher extent from the base training program. The materials modified may contain additional elements to expand certain themes, or parts of materials may be removed as they are not coherent with the requirements of the new educational context. For the canonical content to be modified the teacher should have at his/her disposal a suitably flexible content repository. Usually, due to limited IT competences of teachers it is recommended that adaptation of contents should be done without advanced technological skills. The Content Repository Tool presented in this article enables the creation of repositories which offer such possibilities.

In order to verify the presented method and its tools a repository of teaching materials on protection and management of archeological heritage has been created (Earcheology content repository). The repository contains 
approximately four thousand and five hundred Learning Objects in five languages, and about eight hundred units of didactically useful knowledge, which have been described in the language of UCTS. The Repository has been successfully used to create twenty new training programs based on its content.

\section{FORM OF DIDACTIC MATERIALS}

In order to be repeatedly used, didactic materials must have adequate form. It is important to adapt such an approach in which technical structure of materials is correlated to their logical structure. Furthermore, it is important that the content will have such a technical structure that will enable multiple logical divisions. This requirement is a reflection of the intuition that the author while creating the material will give it one (base) logical structure (e.g. by indicating chapters and subchapters). With time, he/she may want to select smaller sections deciding that they can function on their own outside the initial context. Every didactician working with e.g. PowerPoint type presentations is familiar with these practices. Creation of new presentations from several ones created previously is a natural behavior. Similar behavior is anticipated of authors creating content for distance learning. If they choose to work in one available authoring tool, no difficulties will appear. The content will be corrected and modified in such a tool. Problems may arise if the new logical content division is done beyond the authoring tool in which the content was created, e.g. content repository. In such a situation, inadequate technical structure may make it impossible to divide content and reuse its components.

To avoid this type of problems, prior to creating a content, it is necessary to adapt a structure that will allow for its greater processing flexibility. A good solution is to take an approach in which content are formed as so called elearning courses. An e-learning course has the following characteristics [6]:

- It contains multimedia and interactive elements which improve the attractiveness of the contents and teaching efficiency;

- It has a hierarchical structure which follows the principle of dividing contents into independent units of knowledge, so called Learning Objects;

- It is suited to be placed in any system of distance learning by the fact that it has been recorded in a specification such as SCORM i.e it should have an appropriate technical structure.

Multimedia and interactive elements increase the efficiency of online learning. They should always complement and expand relevant contents and not be used as mere attraction [2]. Introduction of such elements into elearning courses helps to visualize dynamic processes and phenomena or to illustrate correlations between issues discussed in the text. Components of this type are also used to test progress made by students and to create mechanism for self-verification (self-tests). Despite a significant role of multimedia and interactive elements in distance teaching their presence or absence in an elearning course does not influence the method of content processing in a repository of didactic content. Viewed from this perspective, an e-learning course may contain only text instead of multimedia and interactive elements.

Division of the contents into Learning Objects is an approach that relates directly to the specificity of online teaching. Students are hardly able to master the entire content of a single session of an e-learning course. The study will be disrupted by professional or household duties. Thus, if Learning Objects are divided into sections that can be mastered within three to ten minutes then the entire work becomes more effective. Complexity and large amounts of content may cause Learning Objects to be placed in larger structures, which present selected issues and subjects. Learning Objects will be placed hierarchically in aggregating structures on several levels, depending on how detailed the level is. This method of distribution of material imposes a sequence of work on the content at the same time illustrating correlations between individual sections. This means that students will work on the materials in the order intended by the author.

Content building, while preserving division into Learning Objects and their distribution in hierarchical structures, requires authors to think particularly well in the phase of content conceptualization. The key feature of Learning Object is that it contains a coherent content, i.e. a content that comprehensively discusses a defined (limited) issue, problem or topic in accordance with the pre-set didactic objectives. Division of the material into learning objects should supports multiple content use. To make it happen it is necessary to avoid inclusion of references to other Learning Objects in the text editing phase of the Learning Objects. Therefore authors must avoid phrases such as 'as noted earlier/in the previous chapter/paragraph/unit'. Such references will prove to be misleading for the learner if a given unit is transferred to another section of the material. A certain amount of selfdiscipline is required as well as a change in attitude for authors accustomed to working with traditional texts [3].

E-learning courses are organized in a way that combines learning objects into larger units across a certain hierarchical structure. An important feature of such an approach is that learning units contained within make up a certain whole to discuss a defined (rather large) issue, problem or topic in order to comprehensively achieve a pre-set didactic objective. This definition is rather similar to the definition of a learning object, but the difference between them is considerable. An e-learning course contains a part of the material that the learner must realize within a time period at least in order of magnitude longer than for a learning object. This time period is pre-set every time by the author prior to creation of the e-learning course. Whether the course and its contents fully or only in part meet all the didactic objectives set by the author depends on many factors. For example, it may turn out that all the objectives may be realized by a package made up of several courses. Regardless of into how many elearning courses the content is divided, what matters is whether it realizes the pre-set didactic objectives. This approach seems contrary to technical outlook on content organization, in which a given hierarchical structure may group any didactic content, even those not interconnected.

In the subsequent parts of the article a method will be presented to show how by ascribing interpretation to parts of the material in the UCTS system, correlations between individual components of an e-learning course may be expressed, taking into account their role in the didactic process. To make it possible it is necessary to have a flexible technical specification to represent the content, such as SCORM. 


\section{SCORM - THE TECHNICAL ARCHITECTURE OF THE CONTENT}

SCORM is a popular specification which defines principles used to represent digitalized didactic content, thus allowing to create reusable materials ${ }^{1}$. SCORM makes it possible to launch e-learning courses on numerous distance learning platforms (Blackboard, Moodle, Olat, etc). The standard is supported by all the important systems for distance learning of LMS/LCMS class (Learning Management System/ Learning Content Management System). The underlying feature of the specification is the fact that content can be organized in such a way that will allow for its repeated use. SCORM philosophy is based on the fact that contents are divided into numerous components and as such they are transferred into technical form.

From the technical standpoint SCORM-saved materials are structured as follows:

- Course package - a set of files (with the content, graphics, etc) that may be run from LMS/LCMS system. They are generally zip files, which guarantees transferability between platforms.

- Activity - a structure which allows grouping of SCO's, assets and any other activities.

- SCO (Sharable Content Object) - fundamental SCORM component designed to organize content that may be processed (run, given to student) in LMS/LCMS system, and which may communicate with the system in order to send information about student progress (ex. g. about results of tests taken). SCO may be used to record course components which supply or verify content. In technical terms, SCO is a set of components of asset and resource type.

- Asset, resource, file - auxiliary components used in SCO construction (html files, graphic files, flash, scripts, etc).

SCO is a technical component that may be used to record any content selected by the author. Many approaches view SCO as a technical realization of the idea of Learning Object, i.e. it is assumed that it contains a cohesive set of information which exhaustively tackles a given topic. SCORM, however, does not make such demands. It is at the discretion of the author how much contents will be recorded as SCO and how cohesive they will be. Thus, it is important that the author should be aware of the conditions of technical specification used to express the contents. On the one hand, SCORM makes it possible to record as SCO the entire material that the didactician has, on the other hand it is possible to express a single screen content, well known from didactic presentations, as SCO. The approach in which learning objects are recorded as SCO is beneficial from the viewpoint of creation of repositories supporting reusability.

In the presented method, e-learning courses will always be represented as course package. This means that content thus aggregated will always be coherent and didactically valuable.

\footnotetext{
${ }^{1}$ SCORM is quoted in these deliberations as the most popular technical solution that fully supports content reusability. Other solutions (such as e.g. Tin Can) also may serve as technological platforms used to create repositories with this characteristic.
}

\section{DETERMINING DIDACTIC USEFULNESS OF CONTENT} COMPONENT

Structuring materials as Learning Objects and saving them in SCORM is a good starting point to create reusable repositories. However, such an approach does not answer the following questions:

- Which sections of materials stored in a repository are of standard didactic value?

- Which components may function on their own, i.e. are relevantly cohesive and didactically useful?

- Is it possible to incorporate fragments of content into new structures in such a way that they are relevantly cohesive and didactically useful?

These questions in practice boil down to one: Is it worth to download any component from a repository of didactic materials, for example one SCO or several SCO organized in a hierarchical structure, and use it in a didactic process?

For the components downloaded to be cohesive, didactically useful and devoid of purely technical character it is necessary to develop a method that will allow for interpretation of the components in the context of their didactic character. Thus, if the contents are saved in SCORM, it is not sufficient to relate to their structure because individual elements of this structure (SCO, group of SCO, e-learning course) do not carry any information about the role of the materials in didactic process. SCORM shifts to the author the responsibility to indicate which elements of the structure are didactically useful and which have been introduced only for purely technical or organizational reasons, for example the component has been broken down into smaller units due to its volume, and in consequence individual components should not function independently.

However, to conceptualize content so that their components may be reused many times may be a daunting task for the author. This stems from the fact that in the process of creating contents in a conventional way (e. g. while writing a book) it is not customary to consider multiple uses of its parts (chapters). It is taken for granted that the content will be delivered to student in its totality. Therefore, in structuring content meant for SCORM, where from a technical standpoint all methods of content structuring are possible and feasible (especially when it is regarded as a strictly technical job!) it is essential to develop and apply a more systematic approach which will enable an unambiguous determination of content usefulness.

Besides, SCORM is neutral about the complexity of content. It does not include any curricular taxonomy model that can be used to describe the role of content in the teaching process. However, among Learning Object Metadata (which is part of SCORM) there is taxonPath metadata that can be used to express this information. The SCORM documentation shows possible external curricular taxonomy models that can be used to determine didactic usefulness of content components (Table I) [1].

The taxonomic models above refer to intuitively interpretable notions of the role materials play in a didactic process in a given educational context. Within the method presented in this paper as suitable for interpretation of didactic content a solution is suggested that does not refer to any particular educational context - it is UCTS. 
TABLE I.

POSSIBLE METHODS OF CONTENT INTERPRETATION

\begin{tabular}{|l|l|l|l|}
\hline U.S. Army & $\begin{array}{c}\text { U.S. Air } \\
\text { Force }\end{array}$ & U.S. Marine Corps & $\begin{array}{l}\text { Canadian Armed } \\
\text { Forces }\end{array}$ \\
\hline Course & Course & Course & Course \\
\hline Module & Block & Phase & $\begin{array}{l}\text { Performance } \\
\text { Objective }\end{array}$ \\
\hline Lesson & Module & SubCourse (Annex) & $\begin{array}{l}\text { Enabling } \\
\text { Objective }\end{array}$ \\
\hline $\begin{array}{l}\text { Learning } \\
\text { Objective }\end{array}$ & Lesson & Lesson & Teaching Point \\
\hline Learning Step & $\begin{array}{l}\text { Learning } \\
\text { Objective }\end{array}$ & Task & \\
\hline & & Learning Objective & \\
\hline & & Learning Step & \\
\hline
\end{tabular}

UCTS (Universal Curricular Taxonomy System) is a taxonomic model, designed to interpret didactic content [8]. This model provides a description language to structure didactic materials on several levels. The model can be used to describe materials in SCORM. It can also be used to structure materials in any other form.

UCTS provides the following components that can be used to describe didactic content:

- Curriculum,

- Learning module (or: Module)

- Learning Unit (or: Unit)

The term Curriculum is used to define content that can be deemed as a teaching program i.e. that contains a set of materials which present a given topic in an exhaustive way, and which fulfill certain didactic goals. A Curriculum is made up of any number of Module-type components. These components are arranged in a sequence in which they should be realized by student. A Curriculum can be supplemented by an element of Exam type, which will function as a final test for the entire teaching program.

A Module can be made up of several components of Unit type, or other modules. The entire set mutually complementing each other is meant to cover a given topic in an exhaustive fashion. This component should be supplemented with an exam type element which will verify how well student has mastered the module.

A Unit is the smallest section of materials, which introduces cohesive content and which contains elements to enable students to self verify their progress. A Unit is the smallest section of contents that cannot be divided any further. This reflects the idea that for any didactic material (book, script, PowerPoint presentation) there is a certain threshold below which further sectioning of materials is not possible, although divided contents may still be relevantly valuable. It is assumed that a Unit may be made up of the following elements:

- Learning Object - a section of materials which introduces new contents organized as 'knowledge capsules'. The contents may be delivered as text, text with graphics (drawings, photographs, etc) or as multimedia and interactive content (non-linear graphs, dynamic diagrams and graphs, etc); this element may contain self verification and verification components.

- Exercise - a component designed for self verification. This type of elements should be built in an in- teractive way i.e. it should contain elements of interactive testing (one-choice and multiple choice questions, drag and drop, puzzle, etc).

- Self assessment - a special type of exercise which enables students to verify their progress in a given section of contents. Questions in this component should have a cross-sectional character.

- Exam - a component to verify students' progress. Questions in this component may be drawn at random from pools of questions, or given in a fixed set. The results should be sent to LMS/LCMS system and made available to teacher.

- References - a list of books to expand on issues discussed,

As for materials in SCORM, these elements may be recorded as independent SCO's or they can be incorporated into a single $\mathrm{SCO}$ (as for example consecutive screens). Table II shows sample components on protection and management of archeological heritage along with UCTS interpretations (browse www.e-archaeology.org/ contentrepository to see detailed structure of indicated elements).

TABLE II.

SAMPLE CONTENT ALONG WITH UCTS INTERPRETATIONS

\begin{tabular}{|c|c|c|}
\hline UCTS & Element name & Element structure \\
\hline Curriculum & $\begin{array}{l}\text { Archaeological heritage } \\
\text { in contemporary Europe }\end{array}$ & 15 Modules \\
\hline Curriculum & $\begin{array}{l}\text { Archaeological heritage } \\
\text { in contemporary Europe } \\
\text { (Second Edition) }\end{array}$ & 21 Modules \\
\hline Curriculum & $\begin{array}{l}\text { School of the past - } \\
\text { archaeological heritage } \\
\text { for teachers }\end{array}$ & 3 Modules \\
\hline Module & $\begin{array}{l}\text { Theorizing Cultural } \\
\text { Heritage }\end{array}$ & 4 Units \\
\hline Unit & $\begin{array}{l}\text { Cultural Heritage - } \\
\text { concept and problems }\end{array}$ & $\begin{array}{l}5 \text { Learning objects } \\
\text { (arranged in } 2 \text { named } \\
\text { subsections) } \\
1 \text { References element } \\
\end{array}$ \\
\hline Unit & $\begin{array}{l}\text { Cultural Heritage - } \\
\text { management through } \\
\text { time }\end{array}$ & $\begin{array}{l}12 \text { Learning objects } \\
\text { (arranged in } 3 \text { named } \\
\text { subsections) } \\
1 \text { References element }\end{array}$ \\
\hline Module & $\begin{array}{l}\text { Geographic Information } \\
\text { System as a method of } \\
\text { management of spatial } \\
\text { data }\end{array}$ & 5 Units \\
\hline Unit & $\begin{array}{l}\text { GIS applications and } \\
\text { history }\end{array}$ & \begin{tabular}{|ll}
3 & Learning objects \\
1 & Exercise \\
1 & References element \\
\end{tabular} \\
\hline Unit & GIS in archaeology & $\begin{array}{l}17 \text { Learning objects } \\
\text { (arranged in } 4 \text { named } \\
\text { subsections) } \\
2 \text { Exercises } \\
\end{array}$ \\
\hline Module & $\begin{array}{l}\text { International conven- } \\
\text { tions and legal frame- } \\
\text { works }\end{array}$ & $\begin{array}{l}2 \text { Modules ("UN and } \\
\text { Unesco conventions" } \\
\text { and "European con- } \\
\text { ventions") }\end{array}$ \\
\hline Module & $\begin{array}{l}\text { UN and UNESCO con- } \\
\text { ventions }\end{array}$ & 4 Units \\
\hline Unit & $\begin{array}{l}\text { The Convention for the } \\
\text { Protection of Cultural } \\
\text { Property in the Event of } \\
\text { Armed Conflict }\end{array}$ & 4 Learning objects \\
\hline
\end{tabular}




\section{CONTENT REPOSITORY - TOOL SUPPORTING CONTENT REUSABILITY}

A Content Repository is a tool that allows for digital storage of didactic materials and for creation of new materials based on existing components. The tool was developed to solve the problem of electronic storage of large amounts of resources. A content repository is a piece of software working in WWW environment (www.contentrepository.org). It is designed to create content repositories in SCORM standard (version 1.2 and 2004). It can be used to create monographic or multi-topic repositories. Content Repository has a flexible system of rights to determine user entitlement so as to reflect the specificity of a repository under construction and of organizational conditions of an organization that maintains this repository. Thus it is possible to restrict resource access only to logged-in users or to grant the right to publish contents exclusively to author.

A basic function of Content Repository is to create new structures of knowledge based on existing components. The system enables this in an approach that is analogous to editing, in which editor selects interesting and relevant content. In Content Repository this activity consists of finding materials in the system and incorporating them into existing structures. This tool allows for processing only those components that have been earmarked by the author as didactically useful. This is by ascribing a didactic interpretation to the component and by creating an artifact called Processable Unit (PU).

Processable Unit (PU) is a structure of data isolated from Content Repository, and which serves as a base on which processing of knowledge deemed by authors as didactically useful takes place. Processable Units are created by ascribing didactic interpretation to any SCORM component. PU's created in this way are defined in the system as Basic PU's. UCTS-derived nomenclature or nomenclature derived from any other taxonomic model may be used for didactic interpretation. Content Repository is adapted to simultaneously serve numerous taxonomic models. If UCTS nomenclature is used, entitled users may ascribe one of the following values to a SCORM component (SCO, group of SCO, SCORM package): Unit, Module, Curriculum.

The system enables creation of blank PU's, so-called System PU's. Their role is to aggregate other PU's stored in the system. It is possible to embed any base PU's or other system PU's in system PU's. What is important is that when a content is defined as PU, it determines whether it can be downloaded from the system. Only those content structures can be downloaded from Content Repository that have been defined as PU's in the system.

Processable Units are artifacts isolated from Content Repository which determine the level of content granularity in a repository. The system permits operations on content only by referring to PU's. The tool does not permit to create new content components, i.e. it is not possible to create new SCO's nor is it possible to defragment PU's (that is to divide into smaller units). This also means that while downloading content from repository it is not possible to download single SCO's isolated from the PU in which they have been embedded. Only SCORM packages which have been defined as useful in their totality and defined as PU's by their author can be downloaded from Content Repositories.

\section{USING CONTENT REPOSITORY}

Content Repository enables:

- Browsing and searching resources collected in repository,

- Downloading contents as SCORM packages,

- Creating new learning programs based on collected contents,

- Uploading new contents into repository.

\section{A. Browsing and searching}

Content repository allows for several ways of content browsing and searching. The basic view enables search of collected resources through user- selected filters (Figure 1).

Beside basic filters, users can use advanced options. In this mode the system permits a triple search:

- Word search

- Tag search

- Metadata search.

The first method searches for a user-entered word. The system searches text fields in component metadata descriptions (i.e. which are meant by authors to be filled with texts about component).

Tag search is a method of searching for tags used by authors to describe resources (Figure 2). Values saved in General/Keyword metadata are searched. In Content Repository system a solution has been adopted in which authors can use any word or words as tag [9]. It is also possible to use vocabulary from wordnet based ontology with expert knowledge for tagging [7]. This solution is feasible only if such ontology has been built and installed.

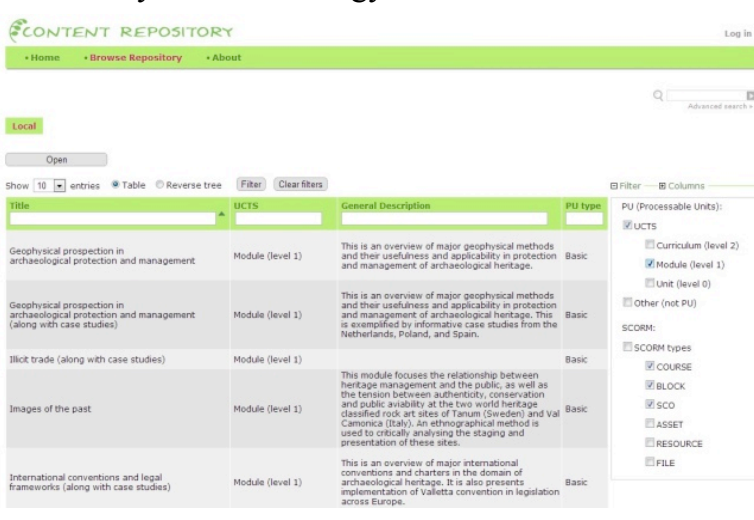

Figure 1. Browsing repository resources

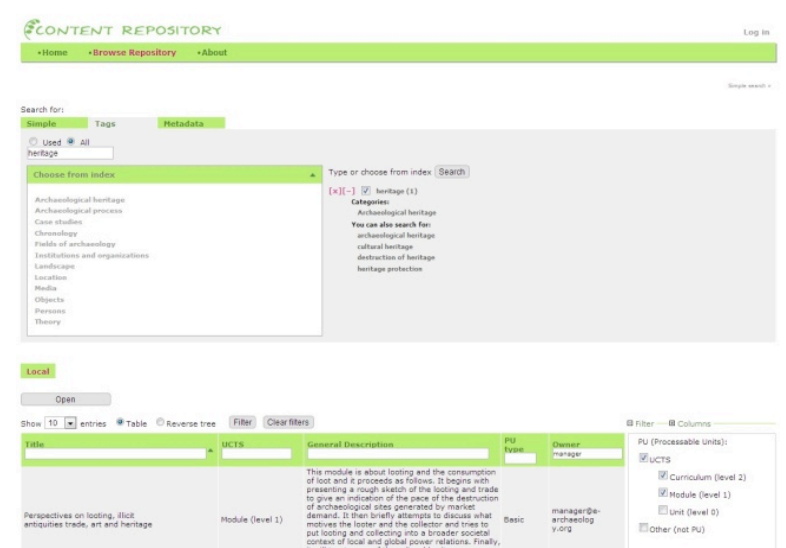

Figure 2. Tag search using wordnet-based ontology 
The last method for resource searching is LOM metadata search. Content repository enables search of all IEEE Learning Object Metadata (LOM), and this mechanism is operated by SCORM. Among metadata there are those that may significantly improve repository search, if they have been filled with contents:

- $<$ general $><$ description $>$ - general description of component,

- $\quad<$ general $><$ language $>$ - language in which materials have been written,

- $<$ general $><$ keyword $>$ - key words to describe component,

- $<$ technical $><$ size $>$ - size of component (ex.g. in MB)

- $\quad<$ technical $><$ duration $>$ - duration of component,

- $\quad<$ educational $><$ interactivityLevel $>$ - level of interactivity, for example medium or high,

- $<$ educational $><$ difficulty $>$ - level of difficulty of material,

- $<$ classification $><$ taxonPath $><$ source $>$ - taxonomic system used to interpret content,

- $<$ classification $><$ taxonPath $><$ taxon $>$ - a particular term within a taxonomy.

When desired elements have been found, user may study the structure of component searched. This function makes it possible to learn about PU structure (Figure 3) or SCORM components, to which didactic interpretation has not been ascribed (but which contain other components).

\section{B. Content downloading}

A logged-in user can download content from repository as SCORM packages. Content Repository allows downloading contents which have gained didactic interpretation in the system, i.e. those that have been defined as PU's. The system does not allow to download SCORM components (SCO, blocks) which are not PU's.

\section{Creating new programs}

Content Repository is a tool which enables creation of new training programs or other knowledge structures, based on content available in the repository. This process may be compared to work of editor, who builds his own training program from repository content. The process of creating new structures comprises:

- Creation of new system PU

- Modification of system PU structure.

The first step creates a blank data structure. The second operation makes it possible to place any searched PU's in the system PU (searched PU's are those that have been published). This step is performed by means of drag and drop mechanism.

\section{Uploading SCORM packages}

Logged-in users may upload SCORM-saved contents in the Content Repository. This functionality jest designed for those users who own e-learning courses and are willing to share them with others. After loading the e-learning course as a SCORM package, the user may ascribe didactic interpretation to its components (Figure 4). This operation creates a base PU. Then it is also possible to describe any element using LOM metadata and to ascribe tags. The user may also determine access rights (publication, presentation of component contents, right to download).

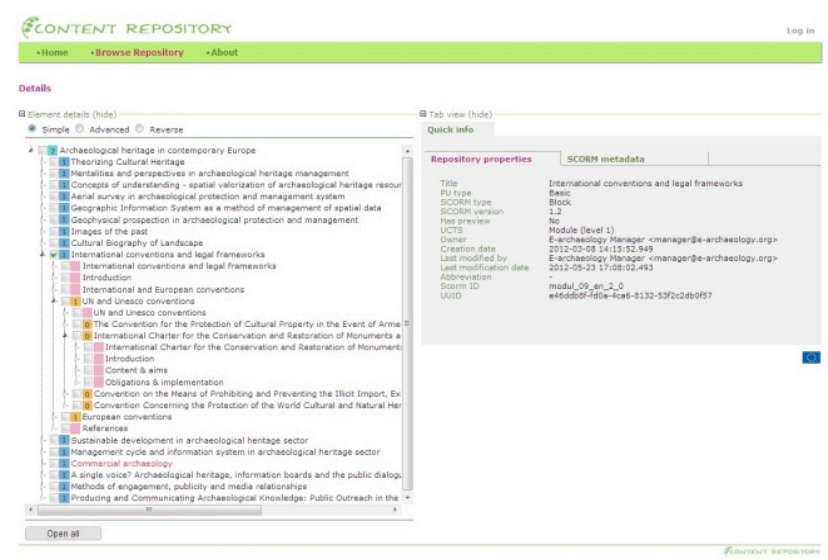

Figure 3. Presentation of PU structure

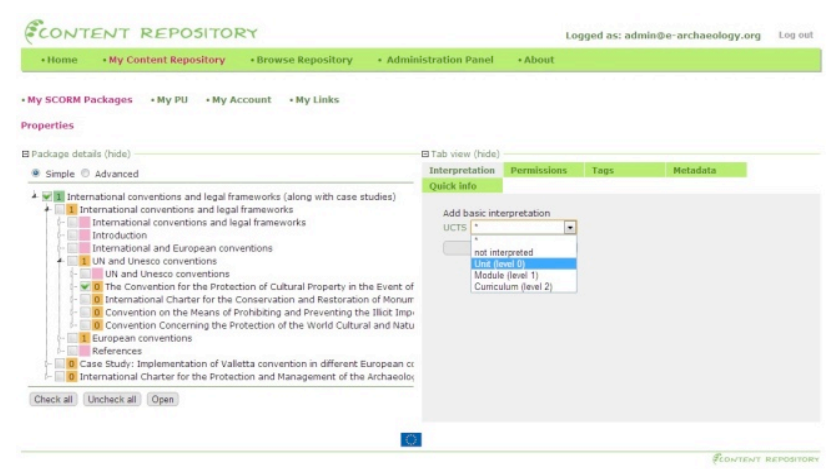

Figure 4. Ascribing didactic interpretation

\section{E-ARCHAEOLOGY CONTENT REPOSITORY}

E-archaeology content repository is a repository of digitalized didactic content in the area of protection and management of archaeological heritage. The repository was built using a Content Repository Tool. UCTS was used for didactic interpretation. The repository is available at: www.e-archaeology.org/contentrepository. The resources collected there are made up of multimedia and interactive e-learning courses. In distance learning they may be used after downloading from the Content Repository and loading into a LMS/LCMS - type system.

All the content in the repository have been developed by specialists in the area of protection and management of archaeological heritage within the framework of two Leonardo da Vinci projects. The first project, "E-learning as a tool of knowledge transfer in the field of protection and management of archaeological heritage", 2007-2009) resulted in developing contents for a learning program "Protection and management of archaeological heritage in contemporary Europe", and in building a set of e-learning courses based on this content [4]. In the course of the second project ("Vocational training system in archaeological heritage based upon e-learning courses", 20102012) the contents was expanded and supplemented.

Digitalized materials stored in E-archaeology content repository were built in a way suited for online teaching [6]. The course components contain interactive and multimedia elements (Figure 5). Those elements introduce content in a non-linear fashion and test students' progress in self-tests. The structure of those materials allows their reusability. The authors divided the content into small cohesive units of knowledge which describe topics in an exhaustive way [3], then these materials were digitalized 
in this form. While implementing the contents in SCORM (version 1.2) it was decided that individual cohesive sections of materials were saved as SCO's. SCO's are of such a size that students should master the contents within three to ten minutes. Thus, this approach meets the requirement of organizing contents as Learning Objects. SCO's making up individual courses are organized hierarchically, using the activity SCORM component. These structures were selected in the course of creating the content, thus reflecting conceptualization of the subject in accordance to author's plan.

The repository contains didactic content in five languages (English, German, Latvian, Polish and Spanish). There are about 4500 SCO's, in particular (approximate values):

- Twenty two training programs (curricula)

- Sixty components of Module type (for English version)

- One hundred seventy-five components of Unit type (for English version)

- Seven hundred SCO's (for English version).

Authors of new learning programs and teachers using the repository content to organize teaching process can take advantage of a range of solutions supporting search process, such as LOM metadata used to describe the content and wordnet based ontology in the area of protection and management of archaeological heritage.

The content in E-archaeology Contents Repository can be used to conduct a didactic process in the area of protection and management of archaeological heritage. They can be incorporated into teaching in the following ways [6]:

- Materials may constitute basic training programs in assisted web-base training;

- They can supplement synchronized training sessions (for example videoconferences), or conventional courses.

In the Leonardo da Vinci project "Vocational training system in archaeological heritage based upon e-learning courses" nine pilot training courses were conducted in the area of protection and management of archaeological heritage, in which contents were created with repository resources [5]. The teachers running the courses created their own training programs suited to the needs of target groups. From a technical standpoint training programs are system PU's defined in Content Repository as Curricula. Table III shows reusability of content components in training programs created in the repository.

\section{CONCLUSIONS}

To enable creation of repositories of reusable teaching materials it is essential for the materials to have a certain form, to be didactically interpreted and to be described in such a way as to simplify search. A good solution is to save content as SCORM and structure them as Learning Objects. It is necessary to ascribe didactic interpretation so that the repository could refer to didactic and not technical conceptualization. Use of SCORM enables division of contents in many different ways; however, not every type of division will ensure comprehensive delivery of a subject to students, nor will it ensure distance learning methodology. UCTS - compatible content conceptualization leaves room for additional didactic requirements. LOM metadata are of particular use in building SCORM contents because they allow comprehensive description of contents, and then effective repository search.

Content Repository enables creation of massive repositories of teaching materials. The system is run by SCORM and its all metadata. It permits loading e-learning courses and other types of knowledge structures, dividing them to suit the teaching needs, and building new teaching programs or other types of knowledge structures using components available. It is possible to download these components as SCORM packages. Thanks to these functionalities courses loaded into the system are not identical with what can be downloaded from the system.

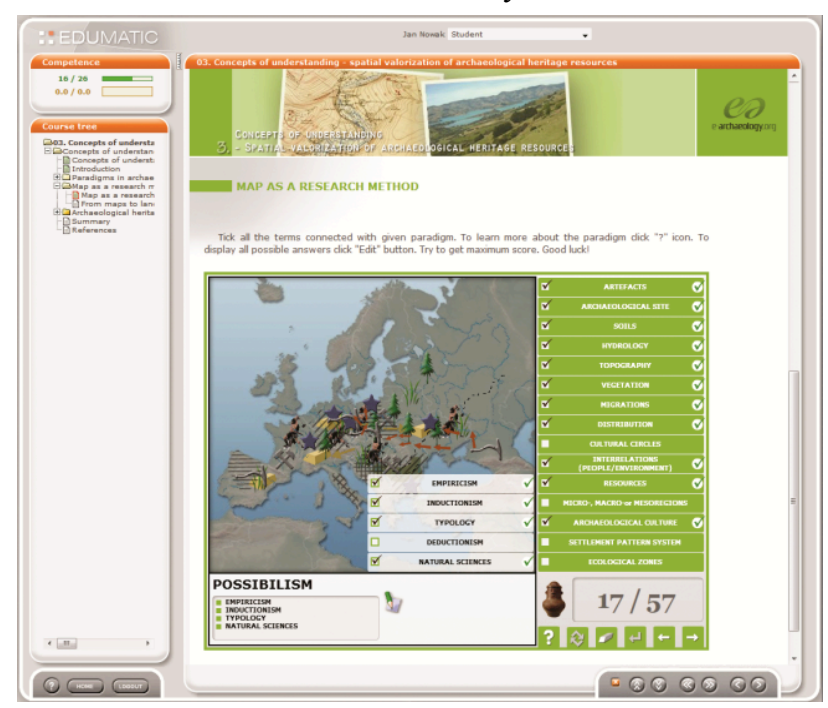

Figure 5. Element of an e-learning course

TABLE III.

REUSABILITY OF CONTENT COMPONENTS

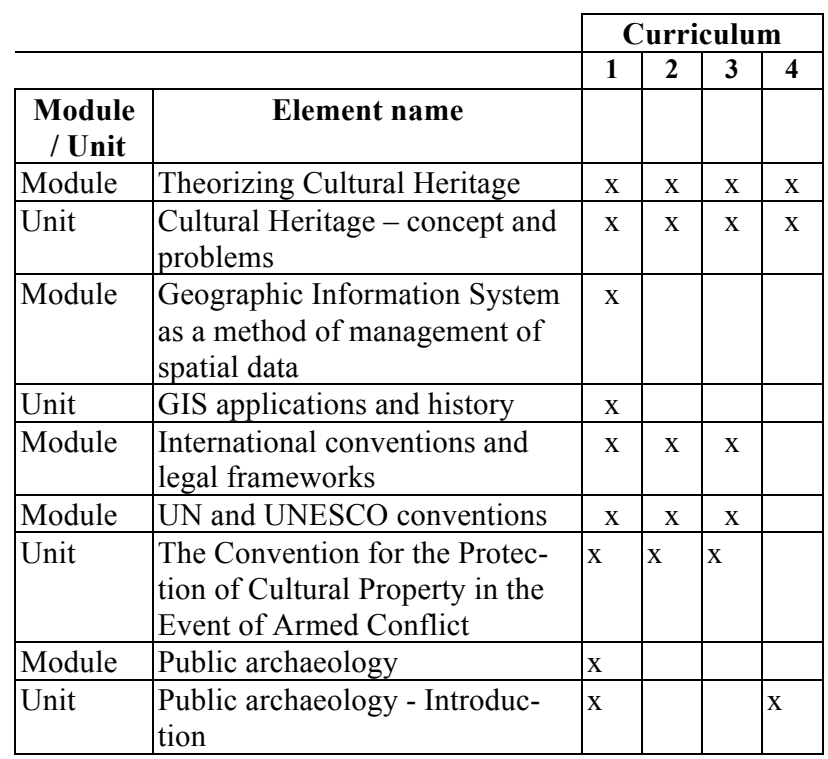

\section{Where:}

$1=$ Archaeological heritage in contemporary Europe (second edition)

$2=$ Archaeology in Action

$3=$ Introduction to Archaeological Heritage Management

$4=$ School of the past - archaeological heritage for teachers 
PAPER

BuILDING E-LEARNING CONTENT REPOSITORIES TO SUPPORT CONTENT REUSABILITY

\section{REFERENCES}

[1] Dodds, P. (2006) SCORM 2004, 3rd Edition, Overview, Advanced Distributed Learning.

[2] Horton W. (2006) E-learning by design, Pfeiffer.

[3] Kok M.S.M. (2009) Teaching by distance learning or face to face: the differences between direct and distance teaching, van Londen H., Kok M. S.M., Marciniak A. (eds.) E-learning Archaeology, Theory and Practice, University of Amsterdam, pp. 143-150.

[4] Marciniak A., (2009) E-learning in archaeological heritage, An example of 'Archaeological heritage in contemporary Europe ' a distance learning course, van Londen H., Kok M. S.M., Marciniak A. (eds.) E-learning Archaeology, Theory and Practice, University of Amsterdam, pp. 41-55.

[5] Marciniak J., Marciniak A., (2012) Innovative Vocational Training System in Archaeological Heritage, Proceedings of the 2nd Edition of International conference The Future of Education, Simonelli Editore.

[6] Marciniak J. (2009) Methodology and e-learning solutions in "Archaeological heritage in contemporary Europe" distance learning course, van Londen H., Kok M. S.M., Marciniak A. (eds.) Elearning Archaeology, Theory and Practice, University of Amsterdam, pp. 56-89.
[7] Marciniak J. (2011) Enhancing tagging systems by wordnet based ontologies. Zygmunt Vetulani (ed.) Proceedings of 5th Language and Technology Conference, November 25-27, 2011.

[8] Marciniak J. (2012) Metody organizacji materiałów dydaktycznych w postaci elektronicznej zapisywanych w standardzie SCORM. Eduakcja. Magazyn edukacji elektronicznej, nr 1(3)/2012, pp. 79-92.

[9] Smith, G. (2008). Tagging: people-powered metadata for the social web. New Riders.

\section{AUTHORS}

J. Marciniak is with the Department of Computer Linguistics and Artificial Intelligence, Faculty of Mathematics and Computer Science, Adam Mickiewicz University, ul. Umultowska 87, 61-614 Poznań, Poland (e-mail: jacekmar@amu.edu.pl).

This work was supported in part by two Leonardo da Vinci projects: "Elearning as a tool of knowledge transfer in the field of protection and management of archaeological heritage" (PL/07/LLP-LdV/TOI/140017) and "Vocational training system in archaeological heritage based upon elearning courses" (2010-1-PL1-LEO05-11465). It is an extended and modified version of a paper presented at the 5th International Conference on Computer Supported Education (CSEDU 2013), 6-8 May 2013, Aachen, Germany. Submitted, 01 December 2013. Published as resubmitted by the author 18 May 2014. 